DOI 10. 18307/2019. 0509

(C) 2019 by Journal of Lake Sciences

\title{
山东省周村水库季节演替中沉积物上覆水溶解性有机物的紫外一可 见与三维荧光光学特征
}

周石䂞 ${ }^{1}$, 孙 悦 $^{1}$, 张艺苒 ${ }^{1}$, 战 江 $^{1}$, 王 函 $^{1}$, 黄廷林 ${ }^{2 * *}$, 丛海兵 ${ }^{3}$, 崔建升 ${ }^{1}$, 李再兴 ${ }^{1}$

( 1 : 河北科技大学环境科学与工程学院, 河北省污染防治生物技术实验室, 石家庄 050018)

( 2 : 西安建筑科技大学环境与市政工程学院,西安 710055)

(3:扬州大学环境科学与工程学院,扬州 225009)

摘 要: 运用三维菼光光谱 (EEMs) 技术结合平行因子分析法 (PARAFAC) 以及紫外一可见光谱技术 (UV-vis), 对周村水 库季节演替过程中沉积物上覆水溶解性有机物 (DOM) 的紫外一可见以及三维荧光光谱特征进行分析. 结果表明: 周村水 库上覆水的总氮、溶解性总氮、总有机碳和溶解性有机碳的季节性差异显著, 并且冬季总氮浓度最高、夏秋季总有机碳浓 度较高; 夏秋季上覆水 DOM 的吸收系数 $a_{254}$ 和 $a_{355}$ 均高于冬春季, 与有机物的分布相一致; 4 个季节上覆水 DOM 的 E3/ E4 均大于 3.5 , 说明 DOM 以富里酸为主, E2/E3 (富里酸占 DOM 的比例) 在夏秋季低于冬春季, 而且各季节 $S_{\mathrm{R}}$ 均大于 1 , 表明 DOM 主要为生物源; 三维苂光通过 PARAFAC 解析出 3 种组分: 类腐殖质 (C1)、可见区富里酸 ( C2 ) 和类蛋白 (C3); 对 3 个组分进行相关性分析, 结果显示 C1、C2、C3 之间具有显著的相关性; DOM 的总苂光强度以及各组分的苂光强度均 呈现出夏秋季高、冬春季低的特征, 且各季节间差异显著; 周村水库 4 个季节的 DOM 生物源指数 $(B I X)$ 在 $0.8 \sim 1.0$ 之间, 表明水库 DOM 具有较强的自生源特征, 与腐殖程度指标 $(H I X)$ 的结果相吻合; 主成分分析显示周村水库上覆水 DOM 的 光谱特征差异明显, 夏秋季的 DOM 光谱特征相近、冬春季的水体 DOM 特征相似; 并且组分 C1、C2、C3 与 DOM 特征参数 $\left(a_{254} 、 \mathrm{SUVA}_{280} 、 H I X 、 F I 、 B I X\right)$ 以及溶解性有机碳呈显著相关. 各荧光组分与水质参数 (溶解性总氮和溶解性有机碳) 的多 元线性回归呈现很好的拟合, 通过建立回归方程可以为以后研究周村水库水体四季的 DOM 光谱特征, 分析水库水体的 有机物污染特征,并为水库水质管理提供技术支持.

关键词: 溶解有机质; 周村水库;光谱特征;紫外一可见光谱;三维苂光光谱

\section{Seasonal variations of ultraviolet-visible and excitation emission matrix spectroscopy characteristics of overlying water dissolved organic matter in Zhoucun Reservoir, Shan- dong Province}

ZHOU Shilei $^{1}$, SUN Yue ${ }^{1}$, ZHANG Yiran ${ }^{1}$, ZHAN Jiang ${ }^{1}$, WANG Han ${ }^{1}$, HUANG Tinglin ${ }^{2 * *}$, CONG Haibing $^{3}$, CUI Jiansheng ${ }^{1} \&$ LI Zaixing ${ }^{1}$

(1: Pollution Prevention Biotechnology Laboratory of Hebei Province, School of Environmental Science and Engineering, Hebei University of Science and Technology, Shijiazhuang 050018, P.R.China)

(2: School of Environmental and Municipal Engineering, Xi'an University of Architecture and Technology, Xi'an 710055, P. R. China)

(3: Department of Environmental Science and Engineering, Yangzhou University, Yangzhou 225009, P.R.China)

Abstract: Based on excitation emission matrix spectroscopy (EEMs) technology combined with the parallel factor analysis ( PARAFAC), and UV-vis spectra, we analyzed the impact of seasonal variations on distribution and spectral characteristics of dissolved organic matter (DOM) in Zhoucun Reservoir. Results showed that the concentration of nitrogen and organic matter exhibited significant seasonal differences, and the reservoir has more total nitrogen and less total organic carbon in winter. The $a_{254}$ and $a_{355}$

* 国家自然科学基金项目 (51478378) 和河北科技大学引进人才科研启动基金项目 (1181278) 联合资助. 2018-1218 收稿;2019-03-06 收修改稿. 周石否 (1987 ), 男,讲师;E-mail:ZSLZhouShilei@ 126.com.

** 通信作者;E-mail: huangtinglin@ xauat.edu.cn. 
in summer and autumn were both higher than those in winter and spring, which was consistent with the changes of organic matter. The E3/E4>3.5 showed that the fulvic acid accounted for the majority proportion in DOM; the concentrations of fulvic acid in summer and autumn were higher than those in winter and spring based on E2/E3. Moreover, the $S_{\mathrm{R}}>1$ indicated the DOM exhibited autochthonous characteristics. One humic-like substances (C1), one fulvic-like substances ( C2) and one protein-like substance (C3) were identified by PARAFAC model, and there exhibited significantly correlation coefficient in C1 \& C2 \& C3; Total fluorescence intensity and the fluorescence intensity of each component exhibited high concentration for summer and autumn and low concentration for winter and spring distribution characteristics. Total fluorescence intensity and the fluorescence intensity of each component exhibited significant seasonal difference. The DOM exhibited strong autochthonous component characteristics based on $B I X$ and HIX indexes; Principal component analysis showed that the spectral characteristics exhibited obvious difference in the whole year, and the DOM spectral characteristics of summer and autumn are similar, and the DOM characteristics of water in winter and spring are similar. Moreover, the C1, C2 and C3 exhibited significantly correlation coefficient with DOM indices (FI, $\beta$ / $\alpha)$ and dissolved organic carbon. Those three components and water quality (dissolved total nitrogen and dissolved organic carbon) of overlying water could be connected with spectral characteristic by nonlinear multiple. From all the results, it could contribute to explore and control the organic carbon pollution sources for the managers of Zhoucun Reservoir in the future.

Keywords: Dissolved organic matter; Zhoucun Reservoir; spectral characteristic; UV-visible spectrum; excitation emission matrix spectroscopy ( EEMs)

溶解性有机质 $(\mathrm{DOM})$ 主要包括亲水性有机酸、类蛋白、类氨基酸、类腐殖酸和碳水化合物等 ${ }^{\left[{ }^{[1]}\right.}$,含有丰 富的碳、氮、磷等要素;DOM 演变过程涉及到水体污染物质的转化,因此会对水体水质演变有重要影响 ${ }^{[2]}$; 而 且水厂在水处理过程中一些含氮 DOM 还会与消毒剂发生反应, 产生消毒副产物, 进而给水质安全带来潜在 的危害 ${ }^{[3-4]}$. 因此,近年来在天然环境水体中有关 DOM 组分、特性以及演变特征的研究成为热点 ${ }^{[5]}$.

紫外一可见以及三维荧光结合平行因子分析技术因其灵敏高效的特征, 被广泛用于表征河流 ${ }^{[6-7]}$ 、河 $\square^{[8-9]}$ 、湖泊 ${ }^{[10-11]}$ 、水库 ${ }^{[12-15]}$ 和湿地 ${ }^{[16]}$ 等不同来源 DOM 的组成和来源. 然而, 目前大多研究往往集中于某一 特定时期或特定区域的 DOM 光谱特征解析. 比如:乔爆琦等 ${ }^{[17]}$ 利用平行因子分析 (PARAFAC) 技术对藻华 暴发季节太湖梅梁湾和开敞区水样中有色可溶性有机物进行三维荧光光谱分析, 发现藻华的长期暴发可以 显著改变湖泊有色可溶性有机物 $(\mathrm{CDOM})$ 的组成, 导致类腐殖酸物质比例提高; 聂明华等 ${ }^{[18]}$ 利用三维苂光 光谱技术,结合平行因子分析法及自组织映射神经网络,对南昌市典型湖泊水体中不同粒径胶体的菼光物 质组分、来源及结构等进行分析; 张博等 ${ }^{[19]}$ 采用化学连续提取与三维苂光光谱相结合的方法研究了䖧湖沉 积物中可提取有机质的组成、结构和空间分布特征,并探讨了可提取态有机质组分与可交换态氮和弱吸附 态磷之间的相关关系; 文杨等 ${ }^{[20]}$ 以沈阳市新开河为研究对象, 考察了冰封期前、后河流底泥中 DOM 组分苂 光特性的变化. 但是, 关于水库季节演替中沉积物上覆水 DOM 光谱特征的研究却鲜有报道.

众所周知,水库不同于一般的天然水体,因其作为城市的供水水源, 担负着保障城市供水水质安全的重 任, 其水质安全影响人民的切身利益 ${ }^{[21-22]}$. 众所周知, 水库沉积物上覆水作为水库沉积物和水体交换的活跃 地带,其水体的水质特征在水库碳、氮、磷等元素的循环中扮演重要角色; 加之水库水体存在热分层现象,使 沉积物上覆水的 DOM 变化特征更不同于一般的水体. 因此,在季节演变的时间尺度下开展周村水库沉积物 上覆水平面空间的 DOM 光谱解析十分必要. 基于此, 本研究利用紫外一可见吸收光谱以及三维苂光光谱分 析技术,分析 2015-2016 年四季演替过程中周村水库沉积物上覆水水体的 DOM 组成和光谱特征. 旨在通 过该研究, 了解沉积物上覆水 DOM 的结构、来源以及对其生态环境效应的影响, 以期为周村水库水体水质 污染防治以及运行管理提供必要的科学依据.

\section{1 材料与方法}

\section{1 采样地点和时间}

周村水库位于山东省本庄市孟庄镇周村南, 总库容 8404 万 $\mathrm{m}^{3}$, 是東庄市主要的城市供水水源地. 本研 究选取 2015 年的 9 月 (秋季)、 12 月 (冬季), 2016 年的 3 月 (春季)、6 月 (夏季) 周村水库 24 个点位的沉积 物上覆水为研究对象, 采样点分布如图 1 所示. 


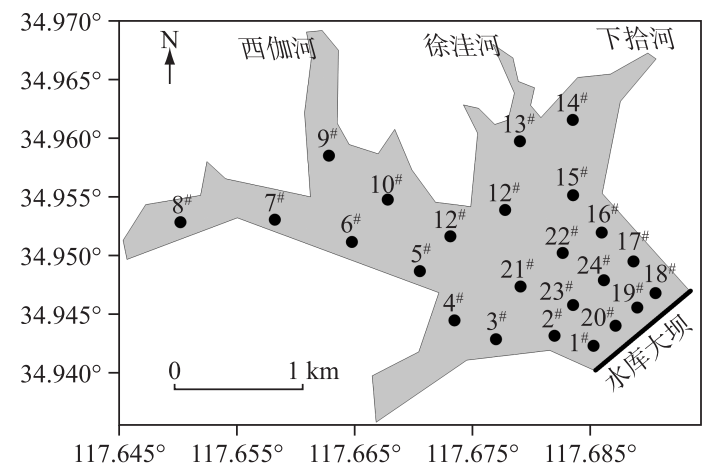

图 1 周村水库沉积物上覆水采样点分布

Fig.1 Location of overlying water sampling sites in Zhoucun Reservoir

\section{2 样品提取及测定}

将收集到的沉积物上覆水水样用 $0.45 \mu \mathrm{m}$ 玻 璃纤维滤膜 (预先 $450^{\circ} \mathrm{C}$ 灼烧 $5 \mathrm{~h}$ ) 过滤得到溶解 性有机物水体样品, 并保存在 $4^{\circ} \mathrm{C}$ 的冰箱内, 在 72 $\mathrm{h}$ 之内完成 DOM 的光谱分析. $24 \mathrm{~h}$ 内完成水样中 溶解性总氮 (DTN)、总氮 ( TN)、总有机碳 ( TOC ) 和溶解性有机碳的测定, 其中 DTN 和 TN 浓度依 据《水和废水监测分析方法》测定 ${ }^{[23]}$, TOC 和溶解 性有机碳浓度用有机碳分析仪测定 ${ }^{[24]}$.

\section{3 紫外一可见吸收光谱的测定}

紫外一可见光谱采用 DR6000 分光光度计 (美 国 HACH 公司) 测定, 以 Mill-Q 水为空白, 用 $1 \mathrm{~cm}$ 石英比色具, 以 $1 \mathrm{~nm}$ 为扫描间隔, 在 $200 \sim 700 \mathrm{~nm}$ 范围内进行吸光度测定. 吸收系数计算公 式为 ${ }^{[25-26]}$ :

$$
\begin{gathered}
a^{*}(\lambda)=2.303 D(\lambda) / r \\
a(\lambda)=a^{*}(\lambda)-a^{*}(700) \cdot \lambda / 700 \\
a(\lambda)=a(440) \exp [S(440-\lambda)]
\end{gathered}
$$

式中, $\lambda$ 为波长, $\mathrm{nm} ; a^{*}(\lambda)$ 为未经散射校正的波长为 $\lambda$ 处的吸收系数, $\mathrm{m}^{-1} ; a(\lambda)$ 为经过散射校正过后的波 长为 $\lambda$ 处的吸收系数, $\mathrm{m}^{-1} ; D(\lambda)$ 为波长 $\lambda$ 处的吸光度; $r$ 为光程路径, $\mathrm{m}$. 本文选取 $a_{254}$ 和 $a_{355}$ 来表示 DOM 的 相对浓度. $S_{\mathrm{R}}$ 为光谱斜率比, 为 $S_{275-295} / S_{350-400}$. 与 $a^{*}(\lambda)$ 相比, $S_{\mathrm{R}}$ 更能反映出 DOM 的来源与分子量信息 ${ }^{[27]}$. $\mathrm{E} 2 / \mathrm{E} 3$ 是 $250 \mathrm{~nm}$ 和 $365 \mathrm{~nm}$ 处的紫外吸光度之比, 其值与相对分子质量大小呈反比 ${ }^{[28-29]}$. E $3 / \mathrm{E} 4$ 是 $300 \mathrm{~nm}$ 和 $400 \mathrm{~nm}$ 处的紫外吸光度之比, 用来衡量腐殖质的腐殖化程度和芳香性. $\mathrm{SUVA}_{260}\left(a_{260} / \mathrm{DOC}\right)^{[27]}$ 用来表征 DOM 疏水组分的含量, $\mathrm{SUVA}_{280}\left(a_{280} / \mathrm{DOC}\right)^{[30]}$ 用来表征 DOM 芳香性的强弱.

\section{4 三维荧光光谱的测定}

三维荧光光谱采用 F97 菼光分光光度计进行测定. 设备的激发波长、发射波长以及扫描速度等参数设 置同黄廷林等 ${ }^{[13]}$ 的研究. 利用超纯水做空白扣除散射影响, 并结合 Delaunnay 三角形内插值法修正去除拉 曼峰散射和瑞利散射 ${ }^{[31]}$. 利用 MATLAB 2014a 软件把 96 个样品的苂光矩阵组合, 采用 N-way 和 DOMFluor 工具箱进行平行因子分析 ${ }^{[32]}$, 并通过核一致性分析确定菼光组分数, 利用折半分析来分析结果的可 靠性 ${ }^{[33]}$.

\section{5 三维荧光光谱的特征指数}

菼光指数 $\left(F I=F_{470} / F_{520}\right)$ 可以评价有机质来源和降解程度, 计算方法见文献 $[34-35]$; 腐殖程度指标 $H I X^{[36]}$ 为 $254 \mathrm{~nm}$ 激光波长下 $435 \sim 480 \mathrm{~nm}$ 间苂光峰值与 $300 \sim 345 \mathrm{~nm}$ 间苂光峰值积分值之商 ( $F_{435 \sim 80}$ ) $\left.F_{300 ~ 345}\right), H I X$ 指数越高则表示 DOM 腐殖化程度越高 ${ }^{[37]}$; 生物源指数指标 $\left(B I X=F_{380} / F_{430}\right)$ 反映有机质自生 源相对贡献率, 同时可以评价生物可利用性的高低 ${ }^{[38]}$; 新鲜度指数 $(\beta: \alpha)$ 为激发波长为 $310 \mathrm{~nm}$ 时苂光发射 波长在 $380 \mathrm{~nm}$ 处苂光强度与苂光发射波长在 $420 \sim 435 \mathrm{~nm}$ 区间最大苂光强度的比值, 是评估水体生物活性 的重要依据.

\section{6 数据分析}

实验数据采用 SPSS (22.0) 软件进行 Pearson 相关性分析和单因素方差分析. 应用 Surfer (12.0) 软件进 行水库沉积物上覆水水体水质及苂光强度分布的绘制.

\section{2 结果与讨论}

\section{1 水库沉积物上覆水中氮和有机碳的分布特征}

夏、秋季周村水库大部分区域沉积物上覆水水体的溶解性有机碳浓度要低于冬、春季 (图 2), 并且各季 
节间均呈显著差异 $(P<0.01)$, 最高值出现在夏季 $(3.16 \pm 0.42 \mathrm{mg} / \mathrm{L})$ (图 $2 \mathrm{~d})$, 最小值出现在春季 $(1.27 \pm 0.31$ $\mathrm{mg} / \mathrm{L}$ ) (图 2c). 而且靠近人库支流 (西北部) 和库湾的部分浓度相对较高. 周村水库中沉积物上覆水中 TN (图 3a) 和 DTN (图 3b) 浓度均在冬季出现最高值, 并且与其他各季节呈显著差异 $(P<0.001)$. 沉积物上覆水 中 TOC 浓度的最大值出现在秋季 $(4.49 \pm 1.41 \mathrm{mg} / \mathrm{L})$, 最小值出现在春季 $(1.80 \pm 0.32 \mathrm{mg} / \mathrm{L})$, 并且与其他各 季节呈显著差异 $(P<0.001)$ ( 图 3c).
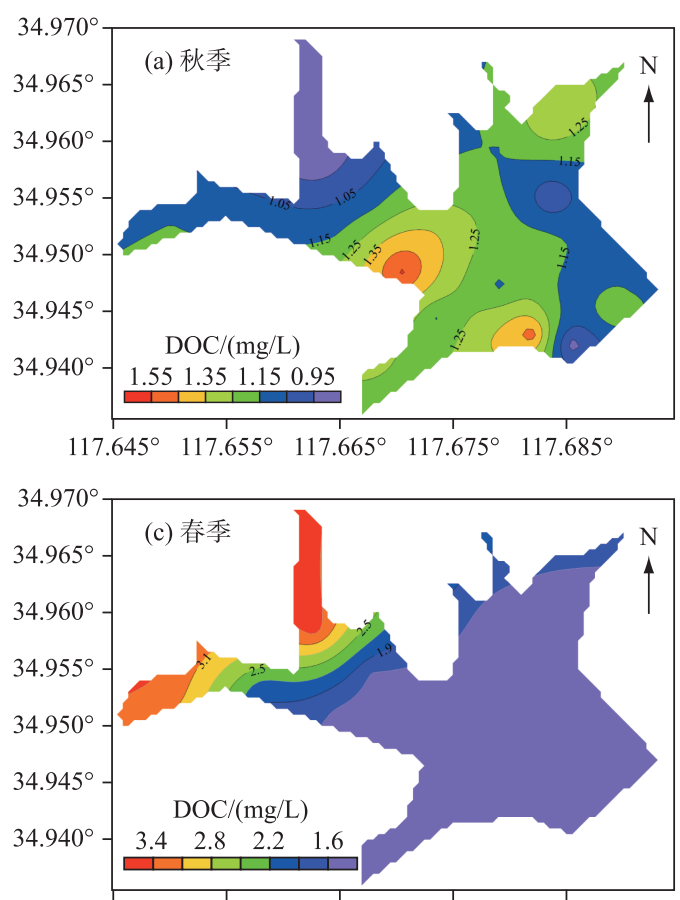

$117.645^{\circ} 117.655^{\circ} 117.665^{\circ} 117.675^{\circ} 117.685^{\circ}$

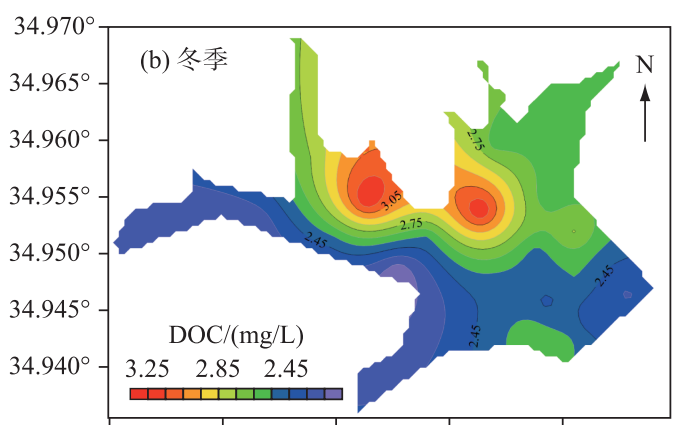

$117.645^{\circ} 117.655^{\circ} 117.665^{\circ} 117.675^{\circ} 117.685^{\circ}$

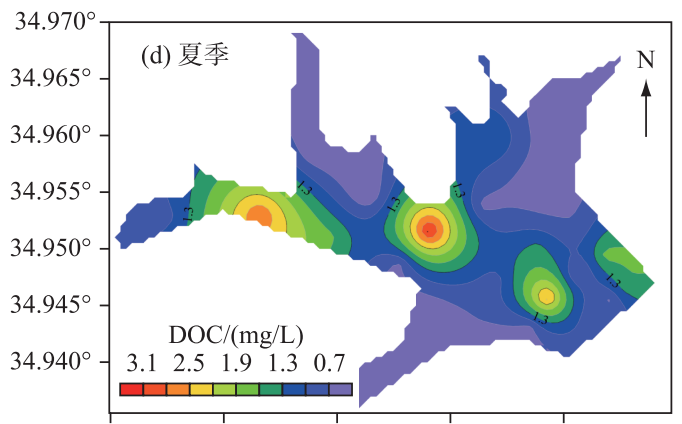

$117.645^{\circ} 117.655^{\circ} 117.665^{\circ} 117.675^{\circ} 117.685^{\circ}$

图 2 周村水库不同季节溶解性有机碳 (DOC) 的分布特征

Fig.2 Characteristics of distribution of dissolved organic carbon(DOC) in Zhoucun Reservoir in different seasons
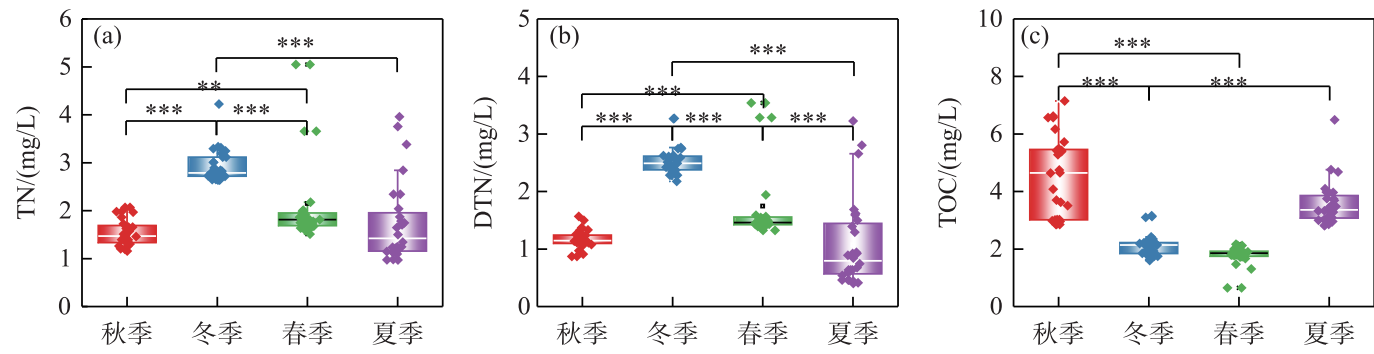

图 3 周村水库不同季节总氮、溶解性总氮和总有机碳的分布特征

Fig.3 Characteristics of distribution of TN, DTN and TOC in Zhoucun Reservoir in different seasons

\section{2 紫外一可见吸收光谱特征参数分析}

本研究用 $a_{254}$ 和 $a_{355}$ 表示 DOM 的相对浓度, 夏、秋季水库水体的 $a_{254}$ 和 $a_{355}$ 明显高于冬、春季 (图 $4 \mathrm{a} 、 \mathrm{~b}$ ), 与溶解性有机碳的分布特征相一致,并且各季节间的 $a_{254}$ 和 $a_{355}$ 呈显著差异 $(P<0.001)$. 有研究表明 ${ }^{[29,39]}$ : $S_{\mathrm{R}}>1$ 时, 表征 DOM 主要为生物源; $S_{\mathrm{R}}<1$ 时, 表征 DOM 主要为外源. 本研究中上覆水的 $S_{\mathrm{R}}$ 值为 $1.09 \sim 1.30$, 但是 4 个季节的 $S_{\mathrm{R}}$ 值均大于 1 (图 4c) , 表明该时期间隙水中的 DOM 主要是生物源. 

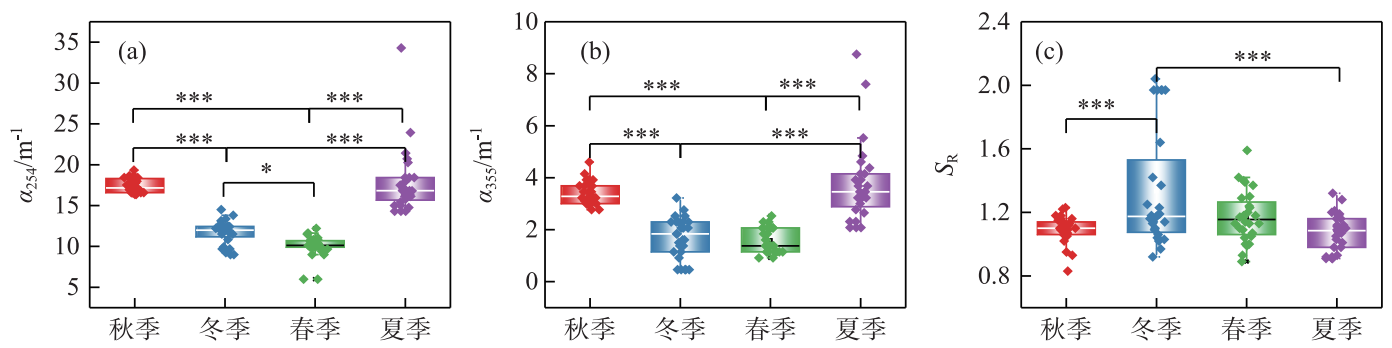

图 4 周村水库上覆水水体 DOM 的 $a_{254} 、 a_{355}$ 和 $S_{\mathrm{R}}(* * *$ 表示 $P<0.001)$

Fig.4 The $a_{254}, a_{355}$ and $S_{\mathrm{R}}$ values of DOM in overlying water of Zhoucun Reservoir

冬、春季周村水库上覆水 DOM 的 $\mathrm{E} 2 / \mathrm{E} 3$ 值较大,夏、秋季分布较集中; 各季节间 $\mathrm{E} 2 / \mathrm{E} 3$ 呈显著差异 (图 $5 \mathrm{a})$; 从整体上看, 冬、春季上覆水中的富里酸占比较大. 一般而言, 当 $\mathrm{E} 3 / \mathrm{E} 4<3.5$ 时腐殖质以腐殖酸为主, $\mathrm{E} 3 / \mathrm{E} 4>3.5$ 时以富里酸为主. 本研究中 $\mathrm{E} 3 / \mathrm{E} 4$ 的均值均大于 3.5 (图 $5 \mathrm{~b}$ ), 说明水库上覆水中 DOM 以富里酸 为主; 冬、春季上覆水的 $\mathrm{E} 3 / \mathrm{E} 4$ 比夏、秋季高, 表明夏、秋季的腐殖化程度较高; 冬季上覆水的 $\mathrm{E} 3 / \mathrm{E} 4$ 与春、 夏、秋季呈显著差异 (图 5b).

春季上覆水 DOM 的 $\mathrm{SUVA}_{260}$ 最高 (图 5c), 表明春季样品的疏水性组分最高; 春季 $\mathrm{SUVA}_{280}$ 同样是最高 的, 其次依次为夏季、冬季和秋季, 表明芳香化程度逐渐减弱 (图 5d) ; 各季节上覆水 DOM 的 SUVA 260 和 SU$\mathrm{VA}_{280}$ 呈显著正相关 $(P<0.01)$, 相关系数达到 0.911 , 表明疏水性和芳香性结构关系密切, 即芳香性结构主要 存在于疏水组分中, 与高洁等 ${ }^{[27]}$ 研究三峡库区 DOM 的结论相一致.
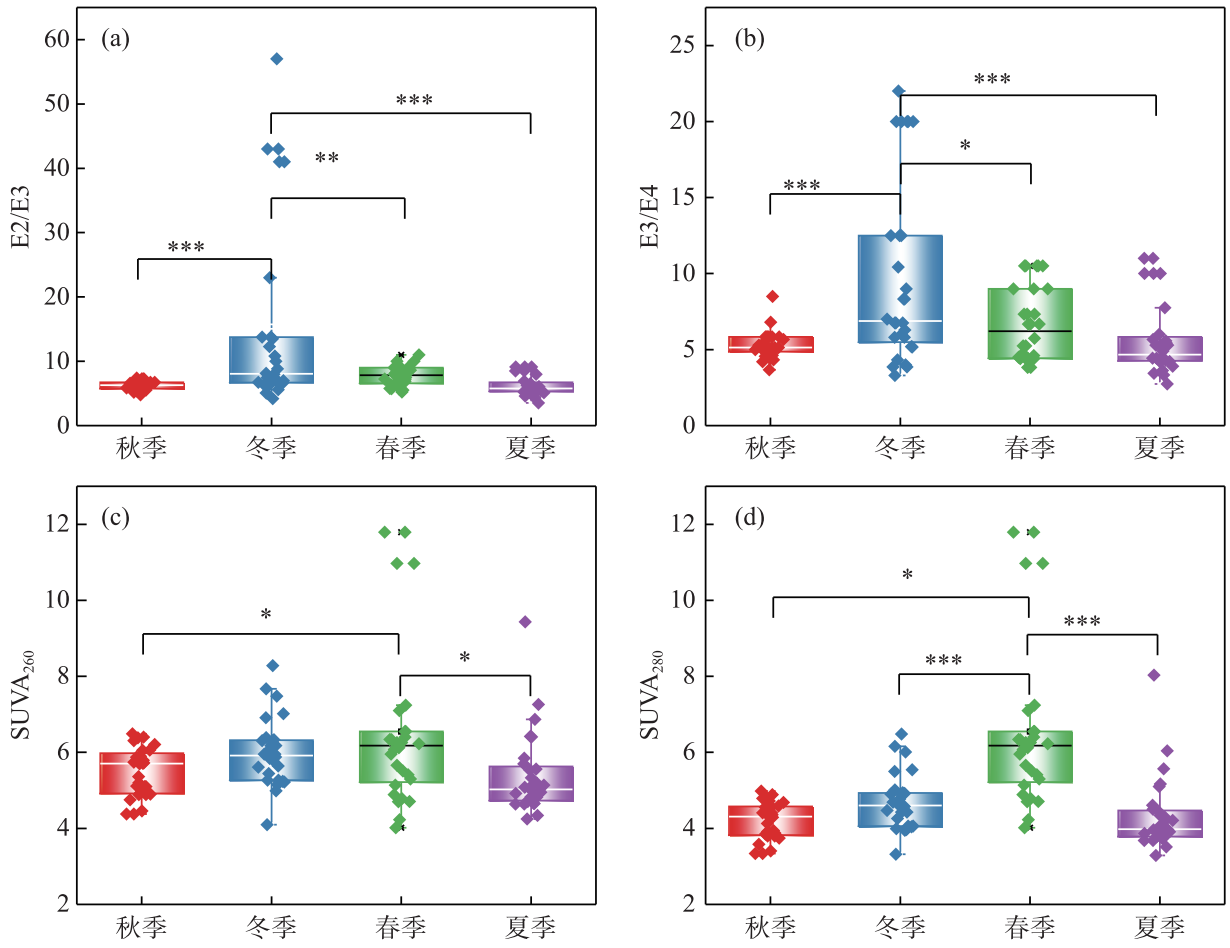

图 5 周村水库上覆水 $\mathrm{DOM}$ 的 $\mathrm{E} 2 / \mathrm{E} 3 、 \mathrm{E} 3 / \mathrm{E} 4 、 \mathrm{SUVA}_{260}$ 和 $\mathrm{SUVA}_{280}$

（ *** 表示 $P<0.001 ， * *$ 表示 $P<0.01 ， *$ 表示 $P<0.05$ )

Fig.5 E2/E3, E3/E4, SUVA 260 and $\mathrm{SUVA}_{280}$ values of overlying water DOM in Zhoucun Reservoir 


\section{3 沉积物上覆水的 DOM 三维荧光光谱及荧光组分分析}

2.3.1 沉积物上覆水 DOM 的三维荧光光谱 为考察水库沉积物上覆水 DOM 的分布特征和组成情况, 选取 了水库主库区 $22^{\#}$ 采样点 4 个季节的样品进行了三维苂光扫描 (图 6), 可以看出, 主库区秋季苂光峰有 3 个: 长波类腐殖质 $(E x / E m=355 \mathrm{~nm} / 460 \mathrm{~nm})$ 、富里酸峰 $(E x / E m=340 \mathrm{~nm} / 415 \mathrm{~nm})$ 和类蛋白峰 $(\mathrm{Ex} / \mathrm{Em}=280$ $\mathrm{nm} / 315 \mathrm{~nm}$ ). 但是随着季节的演替峰的强弱发生变化, 不同季节间差异明显, 因此, 很有必要进一步分析其 变化原因.
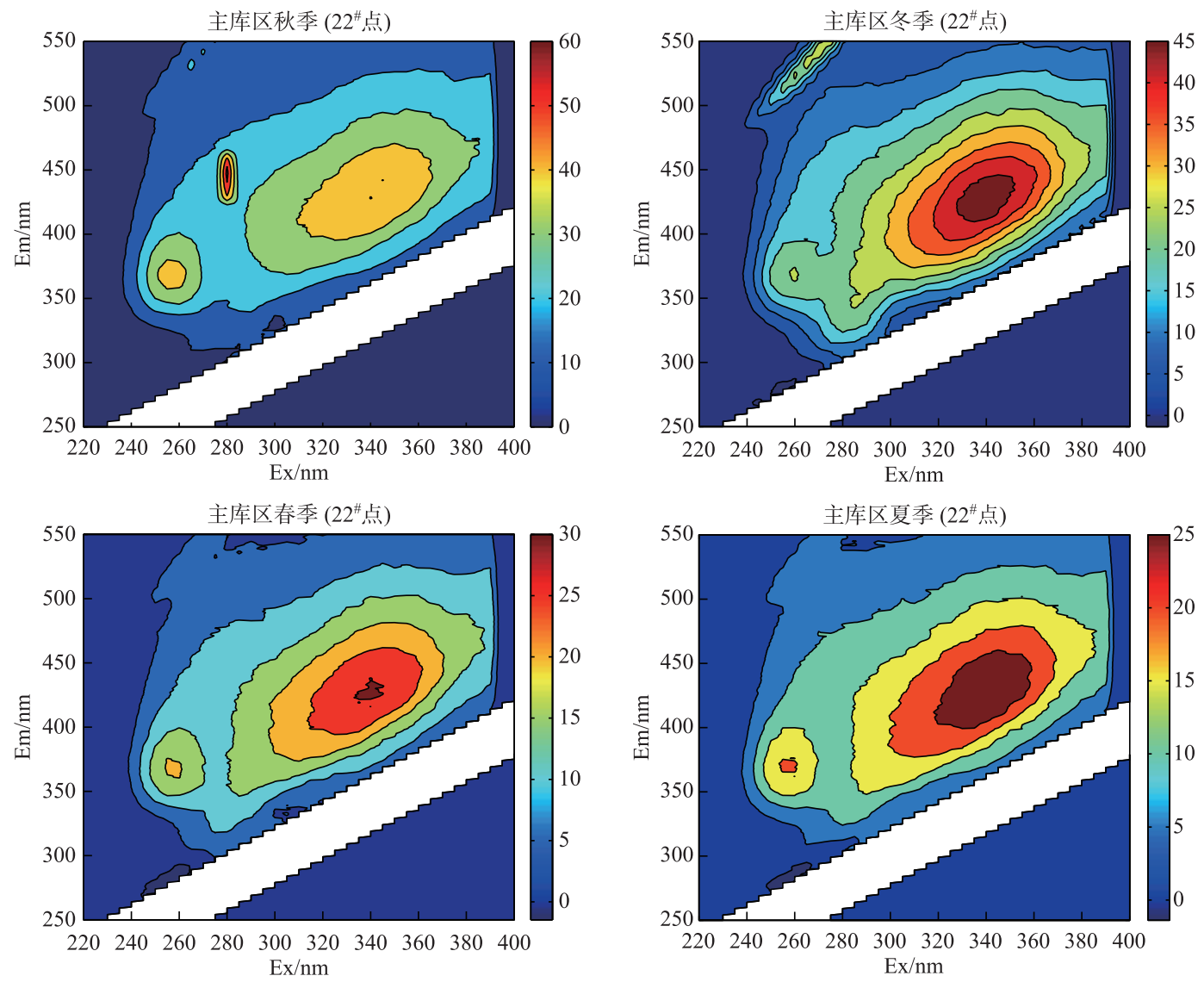

图 6 周村水库主库区不同季节水体的三维苂光光谱

Fig.6 EEM spectra of DOM in the main area of Zhoucun Reservoir in different seasons

2.3.2 沉积物上覆水 DOM 的荧光组分分析 通过平 行因子分析对四季水体样品进行三维苂光解析, 分 析 DOM 的成分构成. 因为 PARAFAC 对组分数很敏 感, 只有选择正确的组分数目, 解析的结果才能反映 真实的谱图. 从图 7 可以看到, 苂光组分从 2 变为 3 时,核一致函数值急剧变小, 而组分从 3 变成 4 时, 核一致函数值变化程度减弱,初步确定成分 $F=3$ 最 合适. 与此同时, 组分为 3 时核一致性系数为 $75.88 \%$, 位于 $80 \%$ 附近, 并且处于急剧下降段, 因此 建立因子数为 3 的 PARAFAC 模型. 与乔显琦等 ${ }^{[17]}$ 解析太湖溶解性有机物荧光组分的分析相一致.

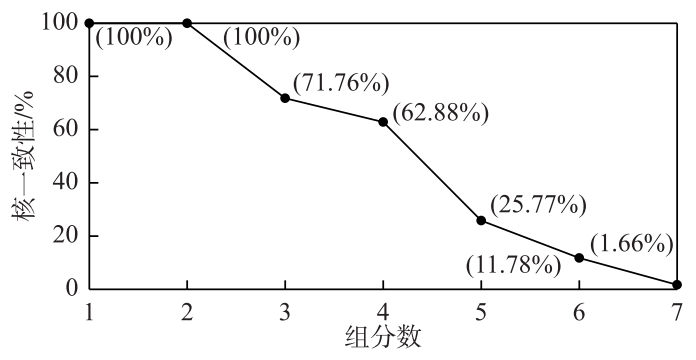

图 7 周村水库水体苂光组分的核一致性检验

Fig.7 Core consistency of EEM samples in Zhoucun Reservoir 
周村水库四季沉积物上覆水 DOM 的苂光光谱图如图 8 所示, 共解析得到 3 种组分, 类腐殖质 (C1)、类 富里酸 (C2) 以及类蛋白 (C3). 结合前人研究成果 (表 1), 综合分析得到: C1 的苂光峰位置是 $355 \mathrm{~nm} / 460$ $\mathrm{nm}(\mathrm{Ex} / \mathrm{Em})$, 为长波类腐殖质 ( $\mathrm{C}$ 峰); $\mathrm{C} 2$ 的苂光峰位置是 $340 \mathrm{~nm} / 415 \mathrm{~nm}(\mathrm{Ex} / \mathrm{Em})$, 为长波类可见区富里 酸; C3 的苂光峰位置是 $280 \mathrm{~nm} / 315 \mathrm{~nm}(\mathrm{Ex} / \mathrm{Em})$, 为类色氨酸.
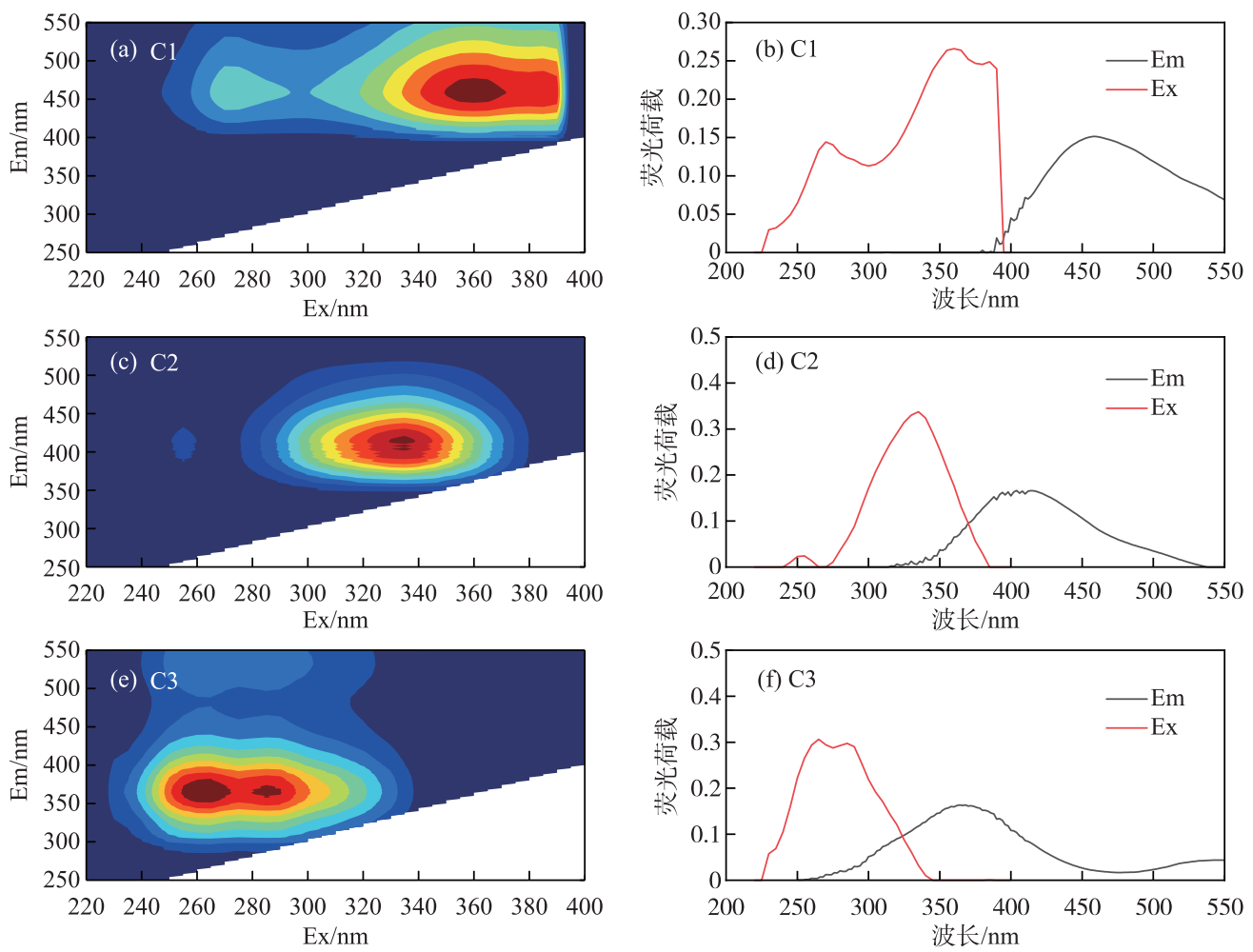

图 8 PARAFAC 解析出的 DOM 中 3 个苂光组分及其激发发射波长位置

Fig. 8 Fluorescence spectra of three components identified by PARAFAC model

表 1 周村水库沉积物上覆水 DOM 的荧光组分特征

Tab.1 Characteristics of components in overlying water of Zhoucun Reservoir

\begin{tabular}{|c|c|c|c|}
\hline 组分 & $\mathrm{Ex} / \mathrm{Em} / \mathrm{nm}$ & 物质 & 文献中的波长/nm \\
\hline C1 & $360 / 460$ & 长波类腐殖质/陆源类腐殖质 & $370 / 440^{[40]}, 350 \sim 440 / 430 \sim 510^{[39]}$ \\
\hline $\mathrm{C} 2$ & $340 / 410$ & 长波类可见区富里酸 & $305 \sim 325 / 410 \sim 420^{[41-42]}$ \\
\hline $\mathrm{C} 3$ & $270 / 360$ & 类蛋白 & $280 / 338 \sim 340^{[43-44]}, 275 / 340^{[45]}$ \\
\hline
\end{tabular}

2.3.3 DOM 的荧光组分强度及分布特征 周村水库沉积物上覆水水体总苂光强度和各组分的菼光强度呈现 夏秋季高于冬春季的特征 (图 9), 并且各季节间均呈现显著差异 $(P<0.01)$. 就苂光组分类腐殖质 ( C1 ) 而 言, 夏季水库上覆水的菼光强度最大, 为 $885.43 \pm 93.72$ A.U., 最小值为春季的 $398.32 \pm 24.86$ A.U., 夏季的 C1 苂光强度约为春季的 2.22 倍, 可能与夏季底层沉积物释放以及径流输人有关; 就苂光组分富里酸 (C2) 而 言, 秋季水库上覆水样品的苂光强度最大, 为 $701.97 \pm 17.74$ A.U., 最小值为春季的 $359.11 \pm 36.84$ A.U., 秋季 的 C2 菼光强度约为春季的 1.95 倍; 就苂光组分类蛋白 (C3) 而言, 夏季水库底层上覆水水体样品的苂光强 度最大, 达到 $661.47 \pm 44.21$ A.U., 最小值为春季的 $342.26 \pm 57.27$ A.U., 夏季的 C3 苂光强度约为春季的 1.93 倍; 总苂光强度最高的为夏季, 达到 $2204.81 \pm 157.52$ A.U., 最低的为春季的 $1099.69 \pm 112.97$ A.U., 夏季的总 荧光强度约为春季的 2 倍. 经平行因子分析得到的 3 种荧光组分中, 各个苂光组分在同一季节的相对含量 
差异不大,夏、秋季的 C1 在 DOM 总苂光强度中的占比达到 $38.69 \%$ 40.07\% , 高于冬、春季的 $36.42 \%$ $36.64 \%$; 冬季 C2 在总苂光强度的占比最大, 达到 $38.51 \% \pm 1.03 \%$, 远高于夏季的 $29.78 \% \pm 1.63 \%$; 夏季的 C3 在 DOM 总苂光强度中的占比达到 $30.14 \% \pm 2.82 \%$, 高于冬季的 $24.85 \% \pm 1.22 \%$ 。
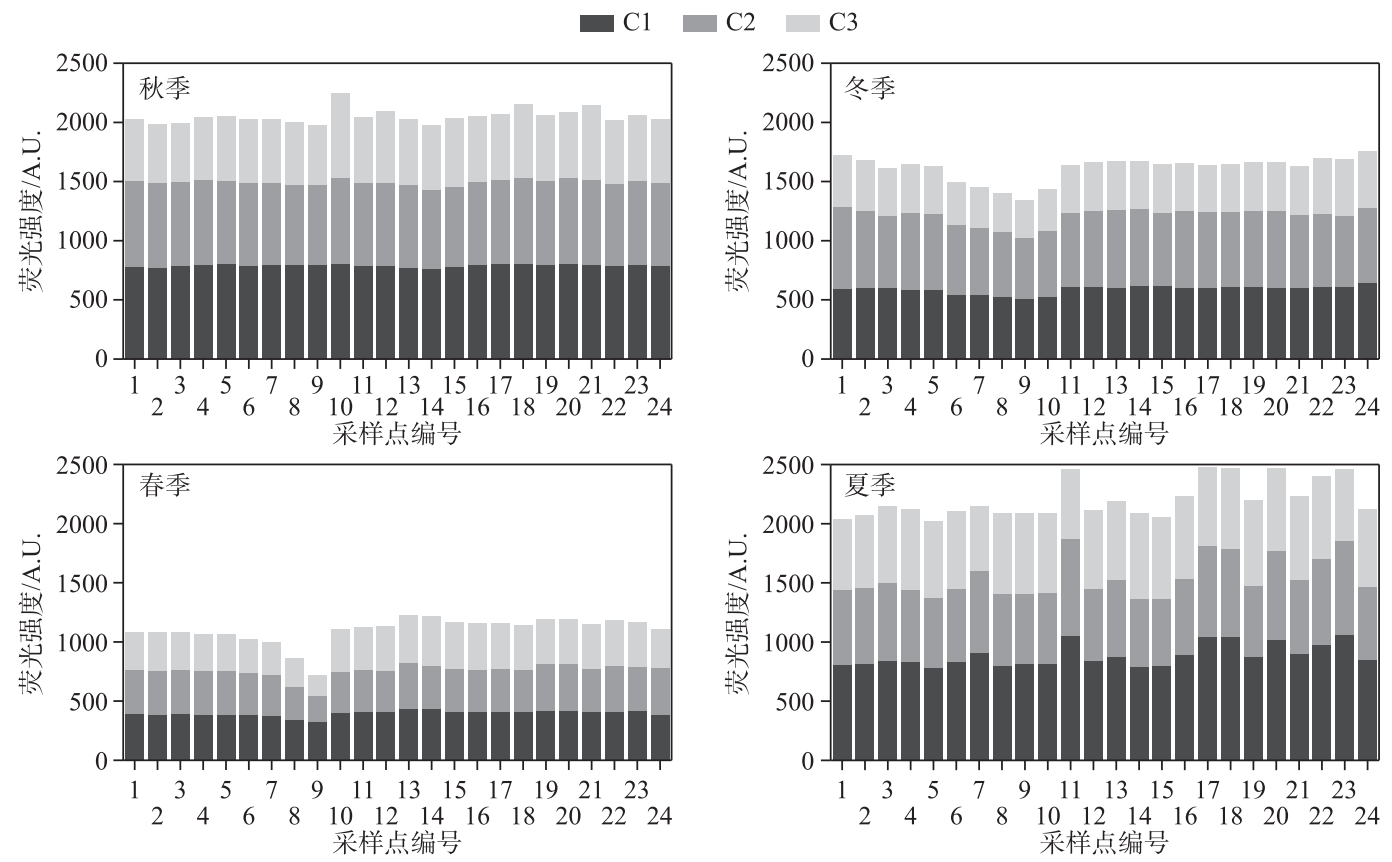

图 9 周村水库沉积物上覆水 DOM 组分苂光强度的季节变化

Fig.9 Seasonal variations of fluorescence intensity of DOM in overlying water of Zhoucun Reservoir

Pearson 相关性分析表明, 周村水库沉积物上覆水 DOM 中类腐殖质 $(\mathrm{C} 1)$ 与可见光区富里酸 $(\mathrm{C} 2)$ 以及类蛋 白 (C3) 两两间存在显著正相关性 (表 2), 表明 3 种组分 具有同源性. 其中组分 $\mathrm{C} 1$ 与组分 $\mathrm{C} 2$ 的相关系数最高, 达到 $0.940(P<0.01)$, 预示着 $\mathrm{C} 1$ 与 $\mathrm{C} 2$ 来源及物质组分 有着较高的相似性.

\section{$2.4 \mathrm{DOM}$ 的荧光特征参数分析}

Huguet 等 ${ }^{[38]}$ 指出 $B I X$ 在 $0.7 \sim 0.8$ 之间时, 具有中度 新近自生源特征; $B I X$ 在 $0.8 \sim 1.0$ 之间时,具有较强的自 生源特征; $B I X$ 大于 1.0 时, 为生物活动产生. 本实验中
表 2 周村水库沉积物上覆水 DOM 中 3 个苂光组分的 Pearson 相关性

Tab.2 Pearson correlation of three components of DOM in overlying water of Zhoucun Reservoir

\begin{tabular}{cccc}
\hline & C1 & C2 & C3 \\
\hline C1 & 1 & & \\
C2 & $0.940^{\text {*** }}$ & 1 & \\
C3 & $0.889^{\text {** }}$ & $0.793^{\text {** }}$ & 1 \\
\hline
\end{tabular}

***表示在 0.01 水平相关性显著 (双尾). $B I X$ 在 $0.8 \sim 1.0$ 之间 (图 10a), 表明周村水库各季节的 DOM 呈现较强的自生源特征. Lavonen 等 $^{[35]}$ 提出 $F I$ 可以作为物质的来源以及 DOM 降解程度的指示指标, $F I>1.8$ 表示以自生源为主, $F I<1.2$ 表示以陆源输人为 主. 冬、春、夏、秋季周村水库上覆水 DOM 的 $F I$ 分别为 $1.87 \pm 0.05 、 1.76 \pm 0.06 、 1.63 \pm 0.04$ 和 $1.72 \pm 0.04$, 冬季 最高, 表明冬季呈现自生源为主的特征, 这与冬季水库径流少、外源输人贡献量低相一致,并且与张博等 ${ }^{[46]}$ 研究发现太湖五里湖水体悬浮物中水溶性有机质 $F I$ 均值为 1.83 、生物源大于陆源输人的结论相一致.

Huguet 等 ${ }^{[38]}$ 指出 $4<H I X<6$ 代表弱腐殖化特征及较强的自生源特征; $H I X<4$ 表示以自生源为主. 本研究 中周村水库沉积物上覆水 DOM 的 $H I X$ 指数都小于 4 (图 10b), 并且春、夏季水体 $H I X$ 指数要低于秋、冬季; 表明春、夏季沉积物上覆水 DOM 的自生源特征更明显, 与 $B I X$ 指数以及紫外一可见吸收光谱 $S_{\mathrm{R}}$ 的结论非常 吻合; 与张海威等 ${ }^{[47]}$ 研究得到的新疆艾比湖人湖河流 DOM 的 $H I X<4$, 主要受到人类活动和微生物活动影响 的结果相一致. 不同季节间 $H I X$ 的差异显著 $(P<0.001)$, 表明不同季节沉积物上覆水的 DOM 来源存在差异. 
新鲜度指数 $(\beta: \alpha)$ 反映了新产生的 DOM 在整体 DOM 中所占的比例, 是评估水体生物活性的重要依据. 周 村水库 $\beta: \alpha$ 分布在 $0.80 \sim 1.05$ 之间（图 10c), 除春、秋季以及秋、冬季样品的 $\beta: \alpha$ 不存在显著差异 $(P>0.05$ ) 外,其他各季节间均存在显著差异 $(P<0.01)$.
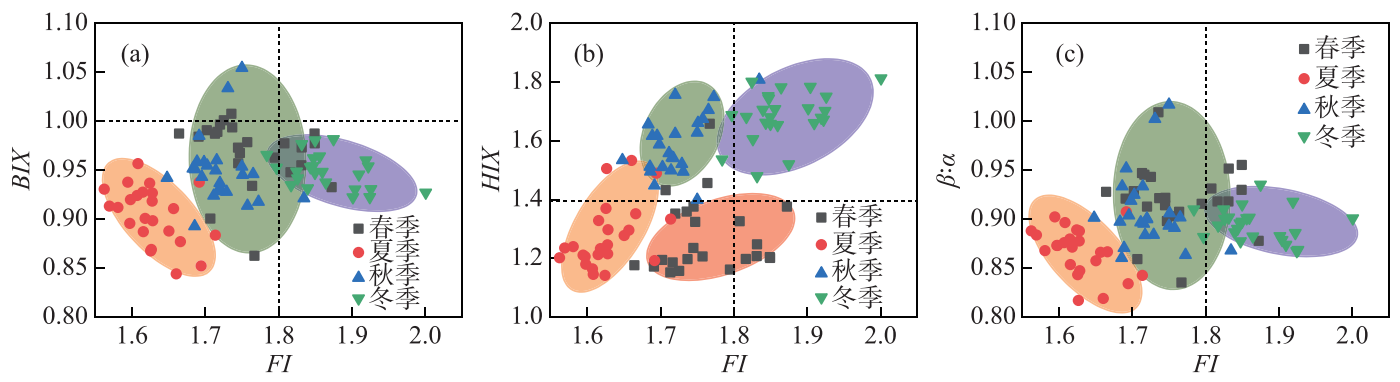

图 10 周村水库不同季节沉积物上覆水中 DOM 的 FI-BIX、FI-HIX 和 FI- $\beta$ : $\alpha$ 分布

Fig.10 FI-BIX, FI-HIX, and FI- $\beta$ : $\alpha$ distributions of DOM in overlying water of Zhoucun Reservoir in different seasons

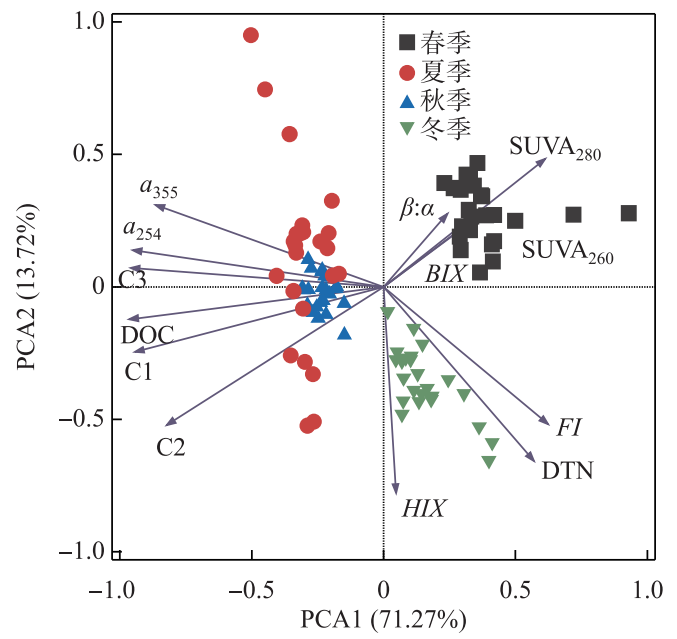

图 11 周村水库不同季节沉积物上覆水 DOM 特征及水质参数的主成分分析

Fig. 11 Principal component analysis DOM and water quality parameters in overlying water of Zhoucun Reservoir in different seasons

\section{$2.5 \mathrm{DOM}$ 的荧光组分与环境因子的相关分析}

为了进一步研究周村水库四季演变过程中 DOM 苂光组分和环境因子的关系, 本研究进行了主成分分 析 (PCA) 和 Pearson 相关性分析. PCA 分析结果 (图 11) 表明, PC1 和 PC2 分别解释了 $71.27 \%$ 和 $13.72 \%$, 总共解释 $84.99 \%$ 的变化, PCA 分析都能够很好地反映 总体的变化. 同一季节的水体样本点分布相对集中, 不同季节间分布差异明显; 冬、春季的样本点位于 PCA1 的正半轴, 而夏、秋季的样本点位于 PCA1 的负 半轴. $a_{254} 、 a_{355} 、 H I X$ 和 DOC 与 $\mathrm{C} 1 、 \mathrm{C} 2 、 \mathrm{C} 3$ 呈正相关, $\mathrm{DTN} 、 F I 、 B I X 、 \beta: \alpha 、 \mathrm{SUVA}_{260}$ 以及 $\mathrm{SUVA}_{280}$ 与 $\mathrm{C} 1 、 \mathrm{C} 2 、 \mathrm{C} 3$ 呈负相关. 综上, 可以侧面解释周村水库不同季节沉 积物上覆水水体 DOM 组分和特征差异.

从周村水库 4 个季节上覆水水体样品的 3 个苂光 组分与 DOM 特征参数以及水质参数的相关性 (表 3 ) 可以看出, 腐殖质组分 $\mathrm{C} 1$ 与 $a_{254} 、 a_{355} 、 \mathrm{SUVA}_{260} 、 \mathrm{SU}-$ $\mathrm{VA}_{280} 、 F I 、 B I X 、 \beta: \alpha$ DTN 以及 DOC 呈显著相关 $(P<$ $0.01)$; 富里酸组分 $\mathrm{C} 2$ 与 $a_{254} 、 a_{355} 、 \mathrm{SUVA}_{260} 、 \mathrm{SUVA}_{280}$ 、 $B I X 、 \beta: \alpha(P<0.05) 、 H I X$ 以及 DOC 呈显著相关 $(P<$ $0.01)$; 类蛋白 $\mathrm{C} 3$ 与 $a_{254} 、 a_{355} 、 \mathrm{SUVA}_{260} 、 \mathrm{SUVA}_{280} 、 F I$ 、

$B I X 、 \beta: \alpha 、 H I X 、 \mathrm{DTN}$ 以及 DOC 呈显著相关 $(P<0.01)$. 同时基于主要的相关性指标 $\left(R^{2}>0.5\right)$ 对菼光组分 $(\mathrm{C} 1$ 、 C2、C3) 和水质指标 (DTN 和 DOC) 进行了多元线性回归, 结果显示多元线性回归拟合的方程很好 (表 4), 将 来可以通过水体的 DOM 特征参数和水质参数对水体 DOM 组分以及水质进行分析, 有利于评估季节演变过 程中溶解性有机物以及水质的特征, 便于水库管理人员对有机污染物和水质进行评价.

\section{3 结论}

1) 紫外一可见光谱特征显示夏、秋季周村水库上覆水 DOM 的吸收系数 $a_{254}$ 和 $a_{355}$ 均高于冬、春季, 与有 机物的分布相一致; 全年上覆水 DOM 以富里酸为主, 主要表现为生物源; $\mathrm{SUVA}_{260}$ 和 $\mathrm{SUVA}_{280}$ 呈显著正相关 $(P<0.01)$, 表明水体样品中 DOM 的芳香性结构主要存在于疏水组分中. 
周石否等:山东省周村水库季节演替中沉积物上覆水溶解性有机物的紫外一可见与三维荧光光学特征 1353

表 3 周村水库沉积物上覆水水体中 3 个苂光组分与特征参数及水质的相关性

Tab.3 Correlation analysis of DOM indices-water quality parameters and three fluorescence components of overlying water in Zhoucun Reservoir

\begin{tabular}{ccccccccccc}
\hline & $a_{254}$ & $a_{355}$ & SUVA $_{260}$ & SUVA $_{280}$ & $F I$ & $B I X$ & $\beta: \alpha$ & $H I X$ & DTN & DOC \\
\hline C1 & $0.772^{* *}$ & $0.672^{* *}$ & $-0.314^{* *}$ & $-0.560^{* *}$ & $-0.559^{* *}$ & $-0.550^{* *}$ & $-0.432^{* *}$ & 0.070 & $-0.343^{* *}$ & $0.893^{* *}$ \\
$\mathrm{C} 2$ & $0.634^{* *}$ & $0.496^{* *}$ & $-0.315^{* *}$ & $-0.644^{* *}$ & -0.192 & $-0.381^{* *}$ & $-0.324^{* *}$ & $0.455^{* *}$ & 0.078 & $0.771^{* *}$ \\
$\mathrm{C} 3$ & $0.817^{* *}$ & $0.747^{* *}$ & $-0.323^{* *}$ & $-0.500^{* *}$ & $-0.724^{* *}$ & $-0.324^{* *}$ & $-0.204^{*}$ & $0.285^{* *}$ & $-0.610^{* *}$ & $0.867^{* *}$ \\
\hline
\end{tabular}

** 表示在 0.01 水平相关性显著 (双尾); * 表示在 0.05 水平相关性显著 (双尾).

表 4 苂光组分与特征参数及水质多元线性回归

Tab.4 Multiple linear regression for DOM indices-water quality parameters and fluorescence components

\begin{tabular}{|c|c|c|}
\hline 回归方程 & 样品个数 & 相关系数 \\
\hline $\mathrm{C} 1=0.376 a_{254}-0.176 a_{355}-0.114 \mathrm{SUVA}_{280}-0.032 F I-0.299 \mathrm{BIX}+0.514 \mathrm{DOC}+1882.25$ & 96 & $0.877^{*}$ \\
\hline $\mathrm{C} 2=0.964 a_{254}-0.479 a_{355}-0.437 \mathrm{SUVA}_{280}+464.59$ & 96 & $0.654^{* * * *}$ \\
\hline $\mathrm{C} 3=0.518 a_{254}-0.287 \mathrm{SUVA}_{280}-0.363 F I+1258.55$ & 96 & $0.829^{* * *}$ \\
\hline $\mathrm{DTN}=0.307 F I-0.301 \mathrm{C} 3+0.305 H I X-3.34$ & 96 & $0.576^{* * *}$ \\
\hline $\mathrm{DOC}=0.155 \mathrm{C} 2+0.094 \mathrm{C} 3-0.345 \mathrm{SUVA}_{280}+0.474 a_{254}-0.147 F I+3.41$ & 96 & $0.910^{* *}$ \\
\hline
\end{tabular}

*** 表示在 0.001 水平相关性显著 (双尾); **表示在 0.01 水平相关性显著 (双尾); *表示在 0.05 水平相关性显著 (双 尾).

2 ) 三维菼光光谱解析得到类腐殖质 (C1)、富里酸 (C2) 和类蛋白 (C3) 各 1 种. 3 种菼光组分具有显著的 相关性 $(P<0.01)$; DOM 总苂光强度以及各组分苂光强度存在显著的季节性差异 $(P<0.001)$; 结合三维菼光 特征指数 $F I 、 B I X$ 以及 $H I X$ 得到周村水库上覆水水体 DOM 具有以自生源为主、低腐殖化的特点.

3) PCA 分析显示周村水库沉积物上覆水 DOM 苂光特征季节差异明显, 并且组分 C1、C2 和 C3 与 DOM 特征参数 $\left(a_{254} 、 \mathrm{SUVA}_{280} 、 H I X 、 F I 、 B I X\right)$ 以及水质参数 $(\mathrm{DOC})$ 存在显著相关性 $(P<0.01)$; 多元线性回归分析 能够很好地预测苂光组分和水质 (DTN 和 DOC) 的变化.

\section{4 参考文献}

[ 1 ] Driscoll CT, Lehtinen MD, Sullivan TJ. Modeling the acid-base chemistry of organic solutes in Adirondack, New York, lakes. Water Resources Research, 1994, 30(2) : 297-306. DOI: 10.1029/93WR02888.

[ 2 ] KirchmanI D ed. The contribution of monomers and other low-molecular weight compounds to the flux of dissolved organic material in aquatic ecosystems. Aquatic ecosystems: interactivity of dissolved organic matter. San Diego: Academic Press, 2003: 218-241.

[ 3 ] Beggs KM, Summers RS. Character and chlorine reactivity of dissolved organic matter from a mountain pine beetle impacted watershed. Environmental Science \& Technology, 2011, 45(13) : 5717-5724. DOI: 10.1021/es1042436.

[ 4 ] Hur J, Lee MH, Song H et al. Microbial transformation of dissolved organic matter from different sources and its influence on disinfection byproduct formation potentials. Environmental Science and Pollution Research, 2013, 20(6) : 4176-4187. DOI : $10.1007 / \mathrm{s} 11356-012-1384-0$.

[ 5 ] Kalbitz K, Schmerwitz J, Schwesig D et al. Biodegradation of soil-derived dissolved organic matter as related to its properties. Geoderma, 2003, 113(3) : 273-291. DOI: 10.1016/S0016-7061(02)00365-8.

[ 6 ] Knapik HG, Fernandes CV, de Azevedo JCR et al. Biodegradability of anthropogenic organic matter in polluted rivers using fluorescence, UV, and BDOC measurements. Environmental Monitoring and Assessment, 2015, 187(3) : 1-15. DOI: 10.1007/s10661-015-4266-3.

[ 7 ] Yu H, Song Y, Du E et al. Comparison of PARAFAC components of fluorescent dissolved and particular organic matter from two urbanized rivers. Environmental Science and Pollution Research, 2016, 23(11) : 10644-10655. DOI: 10.1007/ s11356-016-6232-1. 
[ 8 ] Sun Q, Wang C, Wang P et al. Absorption and fluorescence characteristics of chromophoric dissolved organic matter in the Yangtze Estuary. Environmental Science and Pollution Research, 2014, 21 (5) : 3460-3473. DOI: 10.1007/s11356-0132287-4.

[ 9 ] Canuel EA, Hardison AK. Sources, ages, and alteration of organic matter in estuaries. Annu Rev Mar Sci, 2016, 8(1): 409-434. DOI: 10.1146/annurev-marine-122414-034058.

[10] Kellerman AM, Kothawala DN, Dittmar T et al. Persistence of dissolved organic matter in lakes related to its molecular characteristics. Nature Geoscience, 2015, 8(6) : 454-457. DOI: 10.1038/ngeo2440.

[11] Ziegelgruber KL, Zeng T, Arnold WA et al. Sources and composition of sediment pore-water dissolved organic matter in prairie pothole lakes. Limnology and Oceanography, 2013, 58(3) : 1136-1146. DOI: 10.4319/lo.2013.58.3.1136.

[12] Fang KK, Huang TL, Zhang CH et al. Summer absorption characteristics, spatial distribution and source analysis of CDOM in Zhoucun Reservoir in Huaihe Catchment. J Lake Sci, 2017, 29(1) : 151-159. DOI: 10.18307/2017.0117. [方开凯, 黄廷林, 张春华等. 淮河流域周村水库夏季 CDOM 吸收光谱特征、空间分布及其来源分析. 湖泊科学, 2017, 29 (1) : 151-159.]

[13] Huang TL, Fang KK, Zhang CH et al. Optical characteristics differences of dissolved organic matter from two different full mixed reservoirs in winter based on UV-vis and EEMs. Environmental Science, 2016,37(12): 4577-4585. [黄廷林, 方 开凯, 张春华等. 利用 UV-vis 及 EEMs 对比冬季完全混合下两个不同特征水库溶解性有机物的光学特性. 环境科 学, 2016, 37(12): 4577-4585.]

[14] Huang TL, Fang KK, Zhang CH et al. Analysis of distribution characteristics and source of dissolved organic matter from Zhoucun Reservoir in summer based on fluorescence spectroscopy and PARAFAC. Environmental Science, 2016, 37(9): 3394-3401. [黄廷林, 方开凯, 张春华等. 苂光光谱结合平行因子分析研究夏季周村水库溶解性有机物的分布与 来源. 环境科学, 2016, 37(9) : 3394-3401.]

[15] Lu S, Jiang T, Zhang JZ et al. Three-dimensional fluorescence characteristic differences of dissolved organic matter (DOM) from two typical reservoirs. China Environmental Science, 2015, 35(2) : 516-523. [卢松, 江韬, 张进忠等. 两 个水库型湖泊中溶解性有机质三维荧光特征差异. 中国环境科学, 2015, 35(2): 516-523.]

[16] Chen M, Jaffé R. Photo-and bio-reactivity patterns of dissolved organic matter from biomass and soil leachates and surface waters in a subtropical wetland. Water Research, 2014, 61:181-190. DOI: 10.1016/j.watres.2014.03.075.

[17] Qiao YQ, Jiang HY, Li X et al. Impacts of cyanobacterial blooms outbreak and decline on chromophoric dissolved organic matter in Lake Taihu. J Lake Sci, 2018, 30(4) : 907-915. DOI: 10.18307/2018.0404. [乔显琦, 江海洋, 李星等. 蓝 藻水华暴发和衰亡对太湖有色可溶性有机物的影响. 湖泊科学, 2018, 30(4) : 907-915.]

[18] Nie MH, Huang X, Yan CX et al. Fluorescence characterization of fractionated colloids in different sources of waters based on PARAFAC and SOM. Acta Scientiae Circumstantiae, 2018, 38(9):3672-3681. [聂明华, 黄机, 晏彩霞等. 利用 PARAFAC 及 SOM 研究不同来源及粒径胶体的三维荧光光谱特征. 环境科学学报, 2018, 38(9) : 3672-3681.]

[19] Zhang B, Wang SH, Jiang X et al. Sequential extractions and fluorescene spectroscopy characterization of organic matter in the lake sediment. Acta Scientiae Circumstantiae, 37(8) : 2878-2888. [张博, 王书航, 姜霞等. 湖泊沉积物有机质的 连续提取与菼光光谱特征分析. 环境科学学报, 2017, 37(8): 2878-2888.]

[20] Wen Y, Xue S, Chen J et al. Changes in fluorescence characteristics of dissolved organic matter fractions in the sediments of river before and after the icebound season. Acta Scientiae Circumstantiae, 2015, 35(4) : 1106-1115. [文杨, 薛爽, 陈 静等. 冰封期前后河流底泥中溶解性有机物组分的荧光特性的变化. 环境科学学报, 2015, 35(4) : 1106-1115.]

[21] Zeng MZ, Huang TL, Qiu XP et al. Seasonal stratification and the response of water quality of a temperate reaervoir-Zhoucun Reservoir in north of China. Environmental Science, 2016, 37(4): 1337-1344. [曾明正, 黄廷林, 邱晓鹏等. 我国 北方温带水库一一周村水库季节性热分层现象及其水质响应特性. 环境科学, 2016, 37(4) : 1337-1344.]

[22] Huang TL. In situ control of water pollution of water reservoirs is the prerequisite to improve the safety of drinking water quality. Water \& Wastewater Engineering, 2017, 53(1): 1-3, 69. [黄廷林. 水源水库水质污染原位控制与改善是饮 用水水质安全保障的首要前提. 给水排水, 2017, 53(1): 1-3, 69.]

[23] Editorial board of "Water and wastewater monitoring and analysis method", Ministry of Environmental Protection of the People's Republic of China ed. Monitoring and analysis methods of water and wastewater: fourth edition. Beijing: China Environmental Science Press, 2002. [国家环境保护总局《水和废水监测分析方法》编委会. 水和废水监测分析方 法: 第 4 版. 北京: 中国环境科学出版社, 2002.] 
[24] Huang TL, Zhou SL, Zhang HH et al. Nitrogen removal characteristics of a newly isolated indigenous aerobic denitrifier from oligotrophic drinking water reservoir, Zoogloea sp. N299. International Journal of Molecular Sciences, 2015, 16(5) : 10038-10060. DOI: 10.3390/ijms160510038.

[25] Bricaud A, Morel A, Prieur L. Absorption by dissolved organic matter of the sea (yellow substance ) in the UV and visibledomains. Limnology and Oceanograpgy, 1981, 26(1) : 43-53. DOI: 10.4319/lo.1981.26.1.0043.

[26] Keith DJ, Yoder JA, Freeman SA. Spatial and temporal distribution of coloured dissolved organic matter ( CDOM) in Narragansett Bay, Rhode Island: Implications for phytoplankton in coastal waters. Estuarine, Coastal and Shelf Science, 2002, 55(5) : 705-717. DOI: 10.1006/ecss.2001.0922.

[27] Gao J, Jiang T, Li LL et al. Ultraviolet-Visible (UV-Vis ) and fluorescence spectral characteristics of dissolved organic matter(DOM) in soils of water-level fluctuation zones of the Three Gorges reservoir region. Environmental Science, 2015, 36(1) : 151-162. [高洁, 江蹈, 李璐璐等. 三峡库区消落带土壤中溶解性有机质 (DOM) 吸收及菼光光谱特征. 环 境科学, 2015, 36(1): 151-162.]

[28] Niu C, Zhang YL, Zhu GW et al. Comparison of optical properties of DOM and CDOM in Lake Tianmuhu catchment. Research of Environmental Sciences, 2014, 27(9): 998-1007. [牛城, 张运林, 朱广伟等. 天目湖流域 DOM 和 CDOM 光 学特性的对比. 环境科学研究, 2014, 27(9) : 998-1007.]

[29] Li LL, Jiang T, Yan JL et al. Ultraviolet-visible (UV-Vis) spectral characteristics of dissolved organic matter (DOM) in soils and sediments of typical water-level fluctuation zones of Three Gorges Reservoir areas. Environmental Science, 2014, 35(3) : 933-941. [李璐璐, 江韬, 间金龙等. 三峡库区典型消落带土壤及沉积物中溶解性有机质 (DOM) 的紫外可见光谱特征. 环境科学, 2014, 35(3): 933-941.]

[30 ] Liang J, Jiang T, Lu S et al. Spectral characteristics of dissolved organic matter ( DOM) releases from soils of typical water-level fluctuation zones of Three Gorges Reservoir areas: fluorescence spectra. Environmental Science, 2016, 37( 7): 2506-2514. [梁俭, 江韬, 卢松等. 淹水条件下三峡库区典型消落带土壤释放 DOM 的光谱特征: 若光光谱. 环境科 学, 2016, 37(7) : 2506-2514.]

[31] Zepp RG, Sheldon WM, Moran MA. Dissolved organic fluorophores in southeastern US coastal waters: correction method for eliminating Rayleigh and Raman scattering peaks in excitation-emission matrices. Marine Chemistry, 2004, 89(1) : 1536. DOI: 10.1016/j.marchem.2004.02.006.

[32] Liu HL, Wu XJ, Tian GJ. Three-Dimensional fluorescence spectroscopy combined with parallel factor analysis as a complementary technique for Green Tea characterization. Chinese Journal of Lasers, 2008, 35(5): 685-689. [刘海龙, 吴希军, 田广军. 三维苂光光谱技术及平行因子法在绿茶分析及种类鉴别中的应用. 中国激光, 2008, 35(5) : 685-689.]

[33] Stedmon CA, Markager S. Resolving the variability in dissolved organic matter fluorescence in a temperate estuary and its catchment using PARAFAC analysis. Limnology and Oceanography, 2005, 50(2) : 686-697. DOI: 10.4319/lo.2005.50. 2.0686 .

[34] Cory RM, Mcknight DM. Fluorescence spectroscopy reveals ubiquitous presence of oxidized and reduced quinones in dissolved organic matter. Environmental Science \& Technology, 2005, 39(21) : 8142-8149. DOI: 10.1021/es0506962.

[35] Lavonen E, Kothawala D, Tranvik L et al. Tracking changes in the optical properties and molecular composition of dissolved organic matter during drinking water production. Water Research, 2015, 85: 286-294. DOI: 10.1016/j. watres. 2015.08.024.

[36] Ohno T, Fernandez IJ, Hiradate S et al. Effect of soil acidification and forest type on water soluble soil organic matter properties. Geoderma, 2007, 140(1/2) : 176-187. DOI: 10.1016/j.geoderma.2007.04.004.

[37] Zsolnay A, Baigar E, Jimenez M et al. Differentiating with fluorescence spectroscopy the source of dissolved organic matter in soils subjected to drying. Chemosphere, 1999, 38(1) : 45-50. DOI: 10.1016/S0045-6535(98) 00166-0.

[38 ] Huguet A, Vacher L, Relexans S et al. Properties of fluorescent dissolved organic matter in the Gironde Estuary. Organic Geochemistry, 2009, 40(6) : 706-719. DOI: 10.1016/j.orggeochem.2009.03.002.

[39] Li SD, Jiang QL, Li Y et al. Spectroscopic characteristics and sources of dissolved organic matter from soils around Dianchi Lake, Kunming. Spectroscopy and Spectral Analysis, 2017, 37(5): 1448-1454. [李帅东, 姜泉良, 黎烨等. 环滇池土壤 溶解性有机质 (DOM) 的光谱特征及来源分析. 光谱学与光谱分析, 2017, 37(5) : 1448-1454.]

[40] Zhou QQ, Su RG, Bai Y et al. Characterization of chromophoric dissolved organic matter ( CDOM) in Zhoushan Fishery using Excitation-Emission Matrix Spectroscopy(EEMs) and Parallel Factor Analysis (PARAFAC). Environmental Science, 
2015，36(1): 163-171. [ 周倩倩, 苏荣国, 白芗等. 舟山渔场有色溶解有机物 (CDOM) 的三维菼光-平行因子分析. 环境科学, 2015, 36(1): 163-171.]

[41] Shi J, Wang ZG, Feng K. Characterization techniques of dissolved organic pollutants in wastewater by Three-Dimensional fluorescent spectroscopy and its application in environmental analysis. Journal of Atmospheric and Environmental Optics, 2011, 6(4) : 243-251. [施俊, 王志刚, 封克. 水体溶解有机物三维荧光光谱表征技术及其在环境分析中的应用. 大气与环境光学学报, 2011, 6(4): 243-251.]

[42] OuYang EM, Zhang XH, Wang W. Three-dimensional fluorescence spectroscopy in the analysis of organic pollution type of urban waters. Water Resources Protection, 2007, 23(3) : 56-59. [欧阳二明, 张锡辉, 王伟. 城市水体有机污染类型的 三维苂光光谱分析法. 水资源保护, 2007, 23(3) : 56-59.]

[43] Borisover M, Laor Y, Parparov A et al. Spatial and seasonal patterns of fluorescent organic matter in Lake Kinneret (Sea of Galilee) and its catchment basin. Water Research, 2009, 43(12) : 3104-3116. DOI: 10.1016/j.watres.2009.04.039.

[44] Ni B, Fang F, Xie W et al. Characterization of extracellular polymeric substances produced by mixed microorganisms in activated sludge with gel-permeating chromatography, excitation-emission matrix fluorescence spectroscopy measurement and kinetic modeling. Water Research, 2009, 43(5) : 1350-1358. DOI: 10.1016/j.watres.2008.12.004.

[45] Ziegmann M, Abert M, Müller M et al. Use of fluorescence fingerprints for the estimation of bloom formation and toxin production of Microcystis aeruginosa. Water Research, 2010, 44(1) : 195-204. DOI: 10.1016/j.watres.2009.09.035.

[46] Zhang B, Wang SH, Jiang X et al. Identification of WSOM fluorescence spectral components in suspended solids and correlation analysis with nitrogen forms of Lake Wuli, Lake Taihu. J Lake Sci, 2018, 30(1) : 102-111. DOI: 10.18307/ 2018.0110. [张博, 王书航, 姜霞等. 太湖五里湖水体悬浮物中水溶性有机质 (WSOM) 的苂光光谱组分鉴别及其 与氮形态的关系. 湖泊科学, $2018, \mathbf{3 0}(1): 102-111$.]

[47] Zhang HW, Li F, Li Z et al. Characteristics of three dimensional fluorescence spectra and its correlation with water quality in Jinghe and Bortala River from Lake Ebinur's major inflow tributaries, Xinjiang. J Lake Sci, 2017, 29(5) : 1112-1120. DOI : 10.18307/2017.0509. [张海威, 张飞, 李哲等. 新疆艾比湖主要人湖河流精河与博尔塔拉河三维苂光光谱特 性及其与水质的关系. 湖泊科学, 2017, 29(5) : 1112-1120.] 